\title{
Analisis Laporan Keuangan PT. Smartfren Telecom Tbk Pra dan Pasca Akuisisi
}

\author{
Stevani Fransy Gillis Kaparang \\ Agus Tony Poputra
}

\begin{abstract}
The rapid development of telecomunications industry has changed people's views of the services communications. This is challenge for telecommunication providers so they must perform a variety ways that makes their company still exist in this industry. One way to do is by restructuring through acquisitions.

This research aims is to analyzing the financial performance of PT. Smartfren Telecom Tbk pre and post acquisition. Data used in this research is secondary data that the company's financial statement in 2010-2011. Method of analysis used in is financial ratio analysis such as liquidity ratio, leverage ratio, asset management ratio, and profitability ratio.

The research find that financial performance of PT. Smartfren Telecom Tbk shows the positive impact that can be seen from: (i) level of liquidity and profitability has improved to the post acquisition, (ii) level of leverage has improved because until 2011 experienced a significant decline, (iii) level of assets management is not good because it has decreased in 2011. Thus it can be concluded that the decision to carry out the acquisition demonstrate a positive impact for the company.
\end{abstract}

Keywords: pre and post acquisiton, financial performance analysis, liquidity ratio, leverage ratio, assets management ratio, profitability ratio.

\section{PENDAHULUAN}

Revolusi komunikasi yang signifikan, variatif dan berkelanjutan membuat perusahaan (entitas) penyelenggara jasa telekomunikasi melakukan berbagai cara agar tetap eksis dalam industri jasa telekomunikasi. Salah satu pilihan yang dapat digunakan oleh suatu perusahaan penyelenggara jasa komunikasi agar tetap eksis adalah melaksanakan restrukturisasi dengan cara penggabungan usaha. Restrukturisasi dengan cara penggabungan usaha dapat dilakukan pada suatu entitas dengan melaksanakan akuisisi. Akuisisi dilakukan oleh entitas yang mengakuisisi (bidding firm) untuk mencapai tujuan-tujuan tertentu. Tujuan umum pelaksanaan akuisisi adalah untuk meningkatkan kinerja dari perusahaan hasil penggabungan. Akuisisi juga diharapkan dapat menghasilkan pertumbuhan entitas, meningkatkan dana, mensinergikan proses operasi, pemanfaatan sumber daya manusia, serta meningkatkan likuiditas pemilik.

PT. Smartfren Telecom Tbk adalah salah satu perusahaan penyelenggara jasa telekomunikasi Indonesia yang terdaftar di Bursa Efek Indonesia. Pada bulan Januari 2011 Perseroan melakukan suatu transformasi yaitu PT Mobile-8 Telecom Tbk (FREN) mengakuisisi 57\% saham PT. Smart Telecom senilai Rp 3 Triliun. Pelaksanaan akuisisi ini berupaya untuk memperkuat posisi finansialnya dan merevitalisasi produk penawaran dan citra Perseroan untuk meningkatkan posisi di pasar.

Peningkatan kinerja keuangan PT Smartfren Telecom Tbk yang telah melakukan akusisi tercermin dari laporan keuangan yang diterbitkan perusahaan setiap periode tahun yang bersangkutan. Dengan menganalisis laporan keuangan PT Smartfren Telecom Tbk maka dapat diketahui dampak akuisisi yang telah dilakukan perusahaan terhadap kinerja keuangannya. Jika terjadi peningkatan kinerja dalam hal ini kinerja keuangan maka keputusan management untuk melaksanakan penggabungan usaha dengan cara akuisisi adalah keputusan terbaik bagi kelangsungan hidup perusahaan. 
Berdasar hal tersebut maka permasalahan yang akan dibahas dalam laporan akhir ini adalah bagaimana kinerja pra dan pasca akuisisi pada PT. Smartfren Telecom Tbk. Tujuan dari penelitian ini adalah untuk menganalisis kinerja keuangan PT. Smartfren Telecom Tbk pra dan pasca akuisisi. Dengan demikian maka manfaat yang diharapkan diperoleh dari penelitian ini adalah: (1) sebagai pertimbangan bagi perusahaan untuk menilai keefektivan pelaksanaan penggabungan usaha dan sebagai pertimbangan bagi perusahaan untuk pengambilan keputusan di masa yang akan datang; (2) sebagai bahan referensi bagi pihak lain dalam melakukan penelitian yang berkaitan dengan analisis tentang kinerja keuangan.

\subsection{Metode Penelitian}

1. Unit analisis obyek penelitian ini adalah individual yaitu PT. Smartfren Telecom Tbk.

2. Penelitian ini adalah penelitian deskriptif dimana memberikan gambaran mengenai kinerja keuangan perusahaan berdasarkan analisa-analisa yang dilakukan terhadap data-data keuangan perusahaan.

3. Penulis melakukan penelitian kepustakaan (Library Research) untuk memperoleh data-data yang relevan sebagai bahan penulisan laporan akhir seperti buku-buku, internet, dan sumber-sumber lainnya.

4. Metode pengumpulan data dari penelitian ini adalah secara tidak langsung, dimana penulis mengumpulkan data-data sekunder berupa laporan keuangan perusahaan.

\subsection{Metode Analisis}

Analisis laporan keuangan pada PT. Smartfren Telecom Tbk menggunakan empat rasio keuangan per tahun yakni pada tahun 2010 dan tahun 2011. Rasio-rasio keuangan yang digunakan adalah: (i) Rasio Likuiditas yang terdiri dari Rasio Lancar dan Rasio Cepat, (ii) Rasio Manajemen Aset yang terdiri dari Perputaran Total Aset dan Perputaran Modal Kerja, (iii) Rasio Manajemen Utang yang terdiri dari Rasio Utang dan Long-term Debt to Equity Ratio, (iv) Rasio Profitabilitas yang terdiri dari Return on Total Assets (ROA) dan Return on Total Equity (ROE).

\section{LANDASAN TEORI}

\subsection{Analisis Laporan Keuangan}

Mengacu pada pendapat Palepu, Healy dan Peek (2010) analisis laporan keuangan dikemukakan sebagai suatu aktivitas yang berguna. Keberagaman faktor-faktor kelembagaan membuat manajer tidak mungkin menyajikan informasi mengenai strategi perusahaan secara lengkap. Sehingga penganalisa akan menciptakan informasi mengenai kinerja perusahaan saat ini dan masa depan yang berasal dari kegiatan menganalisa laporan keuangan. (Palepu, dkk., 2010:4).

Salah satu teknik analisa yang digunakan dalam menganalisis laporan keuangan adalah analisa rasio.Dengan analisa rasio penganalisa dapat mengetahui hubungan dari pos-pos tertentu dalam neraca atau laporan laba rugi secara individu atau kombinasi dari kedua laporan tersebut.

\subsection{Jenis-Jenis Rasio Keuangan}

1. Rasio Likuiditas (Modal Kerja) adalah rasio yang mengukur kemampuan perusahaan dalam memenuhi kewajiban jangka pendeknya (Irham, 2012). Likuiditas menunjukkan kemampuan perusahaan memenuhi kewajiban keuangan yang harus segera dipenuhi atau pada saat ditagih. Rasio likuiditas yang digunakan adalah sebagai berikut.

a. Rasio Lancar (Current Ratio), adalah perbandingan antara jumlah aktiva lancar dengan hutang lancar dimana rasio ini menunjukkan bahwa nilai kekayaan lancar (yang segera dapat diuangkan) ada sekian kalinya hutang jangka pendek.

$$
\text { Rasio Lancar }=\frac{\text { Aset Lancar }}{\text { Kewajiban Lancar }}
$$


b. Rasio Cepat (Acid test atau Quick Ratio), merupakan ukuran kemampuan perusahaan dalam memenuhi kewajiban-kewajibannya dengan tidak memperhitungkan persediaan. Karena persediaan memerlukan waktu yang relatif lama untuk direalisir menjadi uang kas.

$$
\text { Rasio Cepat }=\frac{\text { Aset Lancar }- \text { Persediaan }}{\text { Kewajiban Lancar }}
$$

2. Rasio Manajemen Aset, disebut juga rasio aktivitas adalah rasio yang menggambarkan sejauh mana suatu perusahaan mempergunakan sumber daya yang dimilikinya guna menunjang aktivitas perusahaan (Irham, 2012). Rasio manajemen aset ini terdiri atas

a. Perputaran Total Aset (Total Assets Turnover), adalah rasio yang mengukur perputaran dari seluruh aktiva yang dimiliki perusahaan.

$$
\text { Perputaran Total Aset }=\frac{\text { Pen jualan }}{\text { Total Aset }}
$$

b. Perputaran Modal Kerja (Working Capital Turnover), menunjukkan hubungan antara modal kerja dengan penjualan. Dengan demikian rasio ini dapat menunjukkan banyaknya penjualan yang dapat diperoleh perusahaan untuk tiap rupiah modal kerja.

$$
\text { Perputaran Modal Kerja }=\frac{\text { Pen jualan }}{\text { Aset Lancar }- \text { Kewajiban Lancar }}
$$

3. Rasio Manajemen Utang (Leverage), dihitung untuk mengetahui seberapa jauh sebuah perusahaan menggunakan pendanaan melalui utang. Rasio manajemen utang yang disebut juga rasio solvabilitas adalah rasio yang menunjukkan bagaimana perusahaan mampu untuk mengelola utangnya dalam rangka memperoleh keuntungan dan juga mampu untuk melunasi kembali utangnya (Irham, 2012). Beberapa rasio manajemen utang adalah sebagai berikut.

a. Rasio Utang (Debt Ratio), adalah rasio yang mengukur persentase dari dana yang diberikan oleh para kreditor. Rasio utang yang tinggi berarti perusahaan menggunakan utang dengan jumlah yang besar untuk mendanai perusahaan.

$$
\text { Rasio Utang }=\frac{\text { Total Utang }}{\text { Total Aset }}
$$

b. Rasio Hutang Jangka Panjang terhadap Ekuitas (Long-term debt to equity ratio), mengukur sampai sejauh mana komponen hutang jangka panjang dalam struktur modal perusahaan.

$$
\text { Longterm debt to equity ratio }=\frac{\text { Total Hutang Jangka Panjang }}{\text { Total Ekuitas }}
$$

4. Rasio Profitabilitas, bermanfaat untuk menunjukkan keberhasilan perusahaan di dalam menghasilkan keuntungan (Irham, 2012). Investor yang potensial akan menganalisis dengan cermat kelancaran sebuah perusahaan dan kemampuannya untuk mendapatkan keuntungan karena investor mengharapkan deviden dan harga pasar dari sahamnya. 
a. Tingkat Pengembalian Total Aset(Return on Total Assets / ROA), mengukur kemampuan perusahaan dalam menghasilkan laba bersih dengan menggunakan aset yang dimiliki perusahaan.

$$
\text { Tingkat Pengembalian Total Aktiva }=\frac{\text { Laba }(\text { Rugi) Bersih }}{\text { Total Aset }}
$$

b. Tingkat Pengembalian Ekuitas Saham Biasa (Return on Common Equity / ROE), mengukur tingkat pengembalian atas investasi dari pemegang saham biasa.

$$
\text { Tingkat Pengembalian Ekuitas Saham Biasa }=\frac{\text { Laba }(\text { Rugi)Bersih }}{\text { Ekuitas Biasa }}
$$

\section{GAMBARAN UMUM OBJEK PENELITIAN}

\subsection{Sejarah Dan Informasi Umum Perusahaan}

PT Smartfren Telecom Tbk didirikan pada bulan Desember 2002. Pada tahun 2003, Perseroan mengakuisisi dua operator telepon selular berlisensi, yaitu Komselindo dan Metrosel, dan mulai beroperasi sebagai penyelenggara jasa selular dengan menggunakan basis teknologi CDMA (Code Division Multiple Access). Layanan yang pertama kali diluncurkan adalah Layanan Selular Prabayar dengan brand "Fren" yang dioperasikan pada bulan Desember 2003 dengan berbasis jaringan CDMA 2000-1X.

Pada awal tahun 2011, Perseroan melakukan aksi korporasi yaitu peningkatan modal ditempatkan dan disetor penuh untuk mengakuisisi PT SmartTelecom (Smartel). Aksi korporasi ini bertujuan untuk melakukan sinergi dengan Smartel dalam berbagai hal, di antaranya pengembangan infrastruktur jaringan, peningkatan efisiensi operasional, perluasan jaringan pemasaran dan penggabungan merek dagang menjadi "smartfren". Perseroan kemudian melakukan perubahan nama dari sebelumnya PT Mobile-8 TelecomTbk menjadi PT Smartfren Telecom Tbk. Pada akhir 2011, Perseroan kembali meluncurkan gebrakan baru dengan mengusung teknologi CDMA EVDO Rev. B yang menghadirkan layanan internet super cepat dengan kecepatan download mencapai 14,7 Mbps. Hal ini semakin memperkuat posisi Perseroan di mata pelanggan sebagai operator nomor satu di layanan data. Pada akhir 2011, jangkauan layanan Perseroan telah mencakup seluruh pulau Jawa-Bali, sebagian wilayah Sumatera Utara dan Sumatera Selatan, Sulawesi, serta Kalimantan. Perseroan memiliki kurang lebih 7,6 juta pelanggan dengan sekitar 16\% pelanggan data, dengan di dukung oleh lebih dari 140 galeri yang tersebar di berbagai kota di Indonesia.

\subsection{Visi Dan Misi Perusahaan}

Visi PT Smartfren Telecom Tbk adalah To Become A Leading Operator That Provides Sustainable Return To All Stakeholder. Misi PT Smartfren Telecom Tbk adalah Provide Best-ValueFor-Money Data And Voice Service PropositionsTo Our Subscribers While Maintaining Technological Leadership And Excellent Customer Experience. 


\section{Ringkasan Keuangan}

Tabel 3.1

Ikhtisar Keuangan Neraca Konsolidasi PT. Smartfren Telecom Tbk

\begin{tabular}{|l|r|r|}
\hline \multicolumn{3}{|c|}{$\begin{array}{c}\text { PT. SMARTFREN TELECOM Tbk } \\
\text { NERACA KONSOLIDASI } \\
\text { 31 Desember 2010- 2011 }\end{array}$} \\
\hline & \multicolumn{1}{|c|}{2010} & \multicolumn{1}{c|}{2011} \\
\hline Total aset lancar & 446.530 .789 .820 & 794.529 .242 .937 \\
Total aset tidak lancar & 4.037 .079 .091 .723 & 11.502 .049 .407 .801 \\
TOTAL ASET & 4.483 .609 .881 .543 & 12.296 .578 .650 .738 \\
Total kewajiban jangka pendek & 2.075 .185 .359 .585 & 3.099 .633 .529 .663 \\
Total kewajiban jangka panjang & 2.527 .907 .395 .435 & 5.927 .973 .226 .410 \\
TOTAL KEWAJIBAN & 4.603 .092 .755 .020 & 9.027 .606 .756 .073 \\
TOTAL EKUITAS & $(119.482 .873 .477)$ & 3.268 .971 .894 .665 \\
Total Kewajiban dan Ekuitas & 4.483 .609 .881 .543 & 12.296 .578 .650 .738 \\
\hline
\end{tabular}

Sumber: data olahan

Tabel 3.2

Ikhtisar Keuangan Laporan Laba Rugi PT. Smartfren Telecom Tbk

\begin{tabular}{|l|r|r|}
\hline \multicolumn{3}{|c|}{ PT. SMARTFREN TELECOM Tbk } \\
LAPORAN LABA RUGI \\
31 Desember 2010 - 2011 \\
\hline Jumlah pendapatan usaha & \multicolumn{1}{|c|}{2010} & \multicolumn{1}{c|}{2011} \\
Jumlah beban usaha & 376.511 .377 .567 & 954.331 .088 .460 \\
LABA (RUGI) USAHA & 1.244 .775 .882 .804 & 3.175 .959 .127 .642 \\
(Beban) Penghasilan lain-lain bersih & $(868.264 .505 .237)$ & $(2.221 .628 .039 .182)$ \\
LABA SEBELUM PAJAK & $(1.363 .763 .944 .879)$ & $(2.649 .495 .017 .525)$ \\
LABA (RUGI) BERSIH & $(1.401 .813 .486 .084)$ & $(2.400 .247 .590 .614)$ \\
Laba bersih per saham dasar & $(38,89)$ & $(15,89)$ \\
\hline
\end{tabular}

Sumber: data olahan

\section{PEMBAHASAN PENELITIAN}

Ringkasan perhitungan rasio PT Smartfren Telecom Tbk tahun 2010 dan 2011 adalah:

\begin{tabular}{|l|c|c|}
\hline \multicolumn{1}{|c|}{ Keterangan } & $\mathbf{2 0 1 0}$ & $\mathbf{2 0 1 1}$ \\
\hline 1. RASIO LIKUIDITAS & & \\
\hline Rasio Lancar & $21,52 \%$ & $25,63 \%$ \\
\hline Rasio Cepat & $11,11 \%$ & $19,61 \%$ \\
\hline 2. RASIO MANAJEMEN ASET & & \\
\hline Perputaran total aset & $0,839 \mathrm{kali}$ & $0,07 \mathrm{kali}$ \\
\hline Perputaran modal kerja & $-0,231 \mathrm{kali}$ & $-0,414 \mathrm{kali}$ \\
\hline 3. RASIO MANAJEMEN UTANG & & \\
\hline Rasio hutang & $102,66 \%$ & $73,42 \%$ \\
\hline
\end{tabular}




\begin{tabular}{|l|c|c|}
\hline Rasio hutang jangka panjang terhadap ekuitas & $80 \%$ & $85 \%$ \\
\hline 4. RASIO PROFITABILITAS & & \\
\hline ROA & $-31,27 \%$ & $-19,52 \%$ \\
\hline ROE & $-44,42 \%$ & $-34,57 \%$ \\
\hline
\end{tabular}

\section{Analisis Rasio Likuiditas}

a. Rasio Lancar (Current Ratio)

Pada tahun 2010, rasio lancar PT Smartfren Telecom Tbk adalah sebesar 21,52\% atau 0,21 kali. Hal ini berarti setiap Rp 1,- hutang lancar dijamin dengan aktiva lancar sebesar Rp 0,21. Pada tahun 2011 terjadi peningkatan sebesar 4,11\%, yang berarti rasio Lancar perusahaan meningkat menjadi sebesar $25,63 \%$. Hal ini menunjukkan setiap Rp 1,- hutang lancar dijamin dengan Rp 0,25 aset lancar. Dapat disimpulkan bahwa PT Smartfren Telecom Tbk berada pada keadaan illikuid yakni tidak mampu memenuhi liabilitas lancar tepat pada waktunya karena perusahaan memiliki liabilitas lancar yang lebih besar dari aset lancarnya.

b. Rasio Cepat (Quick Ratio)

Rasio cepat PT Smartfren Telecom Tbk pada tahun 2010 adalah sebesar 11,11\% atau 0,11 kali, yang berarti setiap Rp 1,- hutang lancar dijamin oleh Rp 0,11 aset lancar. Pada tahun 2011 rasio cepat mengalami peningkatan 8,5\%. Sehingga rasio cepat PT Smartfren Telecom Tbk menjadi 19,61\%, yang berarti setiap Rp 1,- hutang lancar dijamin oleh Rp 0,20 aset lancar. Dengan demikian dapat disimpulkan bahwa PT Smartfren Telecom Tbk menggunakan aset lancar diluar persediaan untuk memenuhi kurang lebih seperempat dari kewajiban lancarnya.

\section{Analisis Rasio Manajemen Aset}

a. Perputaran Total Aset (Total Assets Turnover)

Perputaran total aset PT Smartfren Telecom Tbk pada tahun 2010 adalah 0,839 kali. Pada tahun 2011 mengalami penurunan 0,769 kali sehingga perputaran total aset tahun 2011 adalah sebesar 0,07 kali. Penurunan ini disebabkan karena peningkatan total aset yang dimiliki perusahaan cukup signifikan, yang tidak sesuai dengan besaran kenaikan total pendapatan.

b. Perputaran Modal Kerja (Working Capital Turnover)

Perputaran modal kerja PT Smartfren Telecom Tbk pada tahun 2010 adalah -0,231 kali. Pada tahun 2011 mengalami penurunan 0,183 kali sehingga perputaran modal kerja tahun 2011 adalah sebesar $-0,414$ kali. Penurunan ini disebabkan karena terjadi peningkatan yang cukup besar yakni Rp. 1,024,448,170,078,- pada liabilitas lancar yang dimiliki perusahaan. Selain itu aset lancar perusahaan juga mengalami peningkatan yakni sebesar Rp. 347,998,453,117,-. Peningkatan pada liabilitas lancar dan aset lancar yang total kenaikannya keduanya sebesar Rp. 1.372.446.623.195,- ini tidak sejalan dengan peningkatan pada total pendapatan PT Smartfren Telecom Tbk hanya sebesar Rp.577,819,710,893,-. Hal inilah yang mengakibatkan perputaran modal kerja PT Smartfren Telecom Tbk adalah negatif.

\section{Analisis Rasio Manajemen Utang (Leverage)}

a. Rasio Utang (Debt Ratio)

Pada tahun 2010 rasio hutang pada PT Smartfren Telecom Tbk mencapai 102,66\%. Hal ini berarti semua pendanaan PT Smartfren Telecom Tbk yaitu mencapai 102,66\% berasal dari kreditor. Pada tahun 2011 rasio hutang pada PT Smartfren Telecom Tbk mengalami penurunan yang cukup besar yakni mencapai 29,24\% dibandingkan tahun 2010, sehingga mencapai rasio hutang sebesar $73,42 \%$. Namun penurunan capaian rasio hutang pada tahun 2011 ini masih menunjukkan bahwa kreditor menyediakan dana yang lebih besar untuk pendanaan dibandingkan dana dari PT Smartfren Telecom Tbk sendiri. Hal ini menunjukkan 
bahwa PT Smartfren Telecom Tbk hanya menggunakan sedikit dananya untuk kegiatan pendanaan karena sebagian besar pendanaan disediakan oleh kreditor.

b. Rasio Hutang Jangka Panjang terhadap Ekuitas (Long-term Debt to Equity Ratio)

Pada tahun 2010 rasio hutang jangka panjang terhadap ekuitas pada PT Smartfren Telecom Tbk mencapai 80\%. Pada tahun 2011 mengalami peningkatan sehingga rasio hutang jangka panjang terhadap ekuitas mencapai 85\%. Peningkatan rasio ini pada PT Smartfren Telecom Tbk disebabkan oleh total kewajiban jangka panjang dan ekuitas perusahaan mengalami peningkatan yang signifikan nilainya.

\section{Analisis Rasio Profitabilitas}

a. Tingkat Pengembalian Total Aset (Return on Total Assets)

Pada tahun 2010 tingkat pengembalian total aset PT Smartfren Telecom Tbk mencapai 31,27\%. Pada tahun 2011 terjadi peningkatan 11,75\% hingga tingkat pengembalian total aset PT Smartfren Telecom Tbk mencapai 19,52\%. Peningkatan ini disebabkan karena terjadi peningkatan nilai pada total aset perusahaan walaupun perusahaan tetap mengalami kerugian. Pada tahun 2011 tingkat pengembalian total aset PT Smartfren Telecom Tbk mengalami peningkatan yang disebabkan karena perusahaan tetap menderita kerugian bahkan lebih merugi, yang untungnya diikuti dengan peningkatan pada total asetnya.

b. Tingkat Pengembalian Ekuitas Saham Biasa (Return on Common Equity)

Pada tahun 2010 tingkat pengembalian ekuitas saham biasa PT Smartfren Telecom Tbk adalah sebesar -44,42. Pada tahun 2011 tingkat pengembalian ekuitas saham biasa PT Smartfren Telecom Tbk meningkat sehingga mencapai 34,57\%. Peningkatan tingkat pengembalian ekuitas saham biasa tahun 2010 hingga 2011 disebabkan karena adanya perubahan yakni peningkatan pada total ekuitas yang dimiliki PT Smartfren Telecom Tbk. Hal ini disebabkan oleh meningkatnya ekuitas atau modal pemegang saham yang diikuti juga dengan peningkatan pada laba (rugi) bersih.

\section{KESIMPULAN DAN SARAN}

Berdasarkan penelitian ini penulis menarik kesimpulan sebagai berikut.

1. PT Smartfren Telecom Tbk memiliki kinerja keuangan yang cukup baik karena mengalami peningkatan pasca akuisisi yang dilakukan pada awal tahun 2011 walaupun PT Smartfren Telecom Tbk mengalami kerugian. Hal ini tercermin pada analisis keuangan sebagai berikut.

a. PT Smartfren Telecom Tbk memiliki tingkat likuiditas dan profitabilitas yang semakin membaik hingga tahun 2011. Peningkatan pada rasio profitabilitas mencerminkan bahwa PT Smartfren Telecom Tbk berusaha untuk memperbaiki keadaan walaupun Perusahaan masih dalam kondisi merugi. PT Smartfren Telecom Tbk melakukan perbaikan dalam menghasilkan laba dari aktivitas operasionalnya baik yang berasal dari pendapatan usaha, total aset, dan ekuitas. Sedangkan peningkatan pada rasio likuiditas mencerminkan bahwa Perusahaan berusaha untuk memperbaiki tingkat likuiditasnya walaupun hingga tahun 2011 Perusahaan masih berada dalam kondisi illikuid.

b. PT Smartfren Telecom Tbk memiliki tingkat leverage yang kurang baik. Namun jika diperhatikan, rasio utang Perusahaan mengalami penurunan yang cukup signifikan. Penurunan pada rasio utang ini menunjukkan bahwa perusahaan mengurangi pendanaan dalam bentuk utang walaupun jumlahnya masih cukup besar. Jumlah yang masih cukup besar ini terlihat pada Long-Term Debt To Equity Ratio yang mengalami peningkatan sebagai akibat dari meningkatnya total liabilitas tidak lancar Perusahaan.

c. PT Smartfren Telecom Tbk memiliki tingkat manajemen aset yang kurang baik karena mengalami penurunan hingga tahun 2011. Hal ini tercermin pada rasio manajemen aset Perusahaan yang terus mengalami penurunan hingga tahun 2011. Penurunan ini menunjukkan bahwa Perusahaan tidak efektif dalam pengelolaan aset yang dimiliki. 
2. Keputusan PT Smartfren Telecom Tbk (dahulu PT Mobile-8 Telecom Tbk) mengakuisisi 57\% saham PT. Smart Telecom pada awal tahun 2011 menunjukkan dampak yang positif bagi kinerja keuangan perusahaan. Hal ini terlihat dalam posisi keuangan Perusahaan yang semakin menunjukkan peningkatan untuk perbaikan yang terlihat dalam hal-hal berikut.

a. Peningkatan dalam total pendapatan yang diperoleh. Walaupun pendapatan lebih sedikit daripada total beban yang mengakibatkan Perusahaan mengalami kerugian, namun tingkat profitabilitas yang mampu dimiliki Perusahaan berdasarkan rasio profitabilitas menunjukkan suatu tanda perbaikan yakni mengalami peningkatan.

b. Meningkatnya total aset yang dimiliki Perusahaan sebagai akibat dari proses akuisisi yang telah dilakukan. Total aset lebih khusus aset lancar yang mengalami peningkatan ini mengakibatkan tingkat likuiditas Perusahaan juga mengalami peningkatan.

c. Bertambahnya total aset ini juga diikuti dengan bertambahnya total liabilitas yang dimiliki perusahaan. Namun berdasarkan analisis yang telah dilakukan menunjukkan bahwa rasio manajemen utang mengalami penurunan. Hal ini menunjukkan bahwa pendanaan Perusahaan dengan menggunakan utang mengalami penurunan.

Saran penulis dalam penelitian ini adalah sebagai berikut.

1. Meningkatkan jumlah aset lancar yang dimiliki perusahaan. Dengan demikian akan meningkatkan likuiditas perusahaan yaitu kemampuan dalam memenuhi kewajiban lancarnya.

2. Memperhatikan komposisi rasio antara hutang dan ekuitas dengan cermat agar perusahaan dapat mencapai struktur modal yang optimal. Pencapaian struktur modal yang optimal dapat dilakukan dengan pengurangan terhadap total hutang baik hutang jangka panjang maupun hutang jangka pendek agar memperbaiki posisi hutang yang dimiliki perusahaan.

3. Menerapkan cost discipline yaitu efisiensi biaya secara terus-menerus. Dengan perusahaan melakukan efisiensi terhadap biaya-biaya yang digunakan maka total beban perusahaan dapat dikendalikan dan akibatnya dapat meningkatkan laba bersih yang diperoleh perusahaan.

\section{DAFTAR PUSTAKA}

Fahmi, Irham. (2012). Analisis Kinerja Keuangan. Bandung: Alfabeta.

Gibson, C. H. (2009). Financial Reporting and Analysis: Using Financial Accounting Information. $11^{\text {st }}$ editon. South Western: Cengage Learning.

Hery. (2013). Akuntansi Dasar 1 dan 2. Jakarta: PT. Grasindo.

Ikatan Akuntan Indonesia. (2011). Standar Akuntansi Keuangan. Jakarta: Salemba Empat.

Kieso, D. E., Kimmel, P. D., \& Weygandt, J. J. (2010). Accounting Principles. $9^{\text {th }}$ edition. Asia: John Wiley \& Sons Inc.

Peek, E., Healy. P. M., \& Palepu, K. G. (2010). Business Analysis and Valuation. $2^{\text {nd }}$ edition. China: South Western Cengage Learning.

Setyani, A. Y., \& Meriewaty, D. (2005). Analisis Rasio Keuangan Terhadap Perubahan Kinerja Pada Perusahaan di Industri Food and Beverages Yang Terdaftar di BEJ. Paper dipresentasikan pada Simposium Nasional Akuntansi 8, Universitas Sebelas Maret, Surakarta.

Swain, M. R., Stice, J. D., Stice, E. K., Albercht, W. S. (2008). Accounting: Concepts and Applications. $10^{\text {th }}$ edition. USA: Thomson South Western.

PT Smartfren Telecom Tbk. Laporan Keuangan Tahunan 2010-2011. http://www.smartfren.com/ 